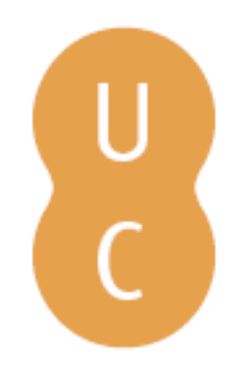

\title{
nommalina
}

\section{A Geografia portuguesa em 1929 na correspondência entre Amorim Girão e Gonzalo de Reparaz Ruiz}

\author{
Autor(es): $\quad$ Garcia, João Carlos; Mendizàbal Riera, Enric \\ Publicado por: Imprensa da Universidade de Coimbra \\ URL \\ persistente: URI:http://hdl.handle.net/10316.2/43486 \\ DOI: $\quad$ DOI:https://doi.org/10.14195/978-989-26-1343-7_16 \\ Accessed : $\quad$ 26-Apr-2023 12:40:57
}

A navegação consulta e descarregamento dos títulos inseridos nas Bibliotecas Digitais UC Digitalis, UC Pombalina e UC Impactum, pressupõem a aceitação plena e sem reservas dos Termos e Condições de Uso destas Bibliotecas Digitais, disponíveis em https://digitalis.uc.pt/pt-pt/termos.

Conforme exposto nos referidos Termos e Condições de Uso, o descarregamento de títulos de acesso restrito requer uma licença válida de autorização devendo o utilizador aceder ao(s) documento(s) a partir de um endereço de IP da instituição detentora da supramencionada licença.

Ao utilizador é apenas permitido o descarregamento para uso pessoal, pelo que o emprego do(s) título(s) descarregado(s) para outro fim, designadamente comercial, carece de autorização do respetivo autor ou editor da obra.

Na medida em que todas as obras da UC Digitalis se encontram protegidas pelo Código do Direito de Autor e Direitos Conexos e demais legislação aplicável, toda a cópia, parcial ou total, deste documento, nos casos em que é legalmente admitida, deverá conter ou fazer-se acompanhar por este aviso.

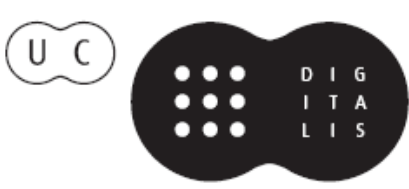




\section{FERNANDA CRAVIDÃO}

\section{IÚCIO CUNHA}

PAULA SANTANA

\section{NORBERTOSANTOS}

(ORG.)

\section{ESPAÇOS E TEMPOS EM GEOGRAFIA}

HOMENAGEM A ANTÓNIO GAMA

IMPRENISA DÁ UNIVERSIDADE DE COIMBRA COIMBRA UNIVERSITY PRESS

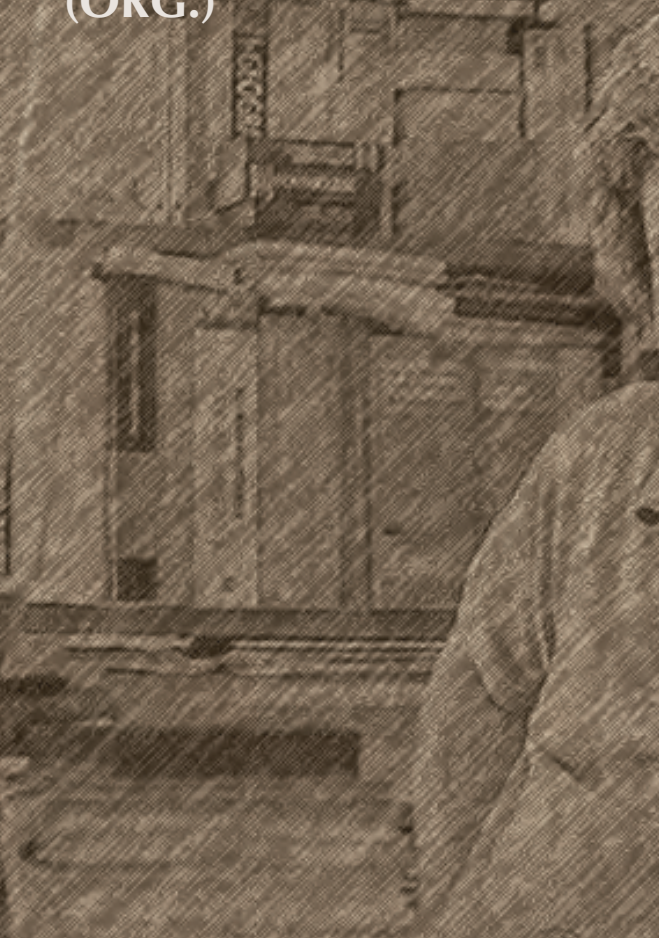




\title{
A GeOgRAFia PORTUGUESA EM 1929 NA CORRESPONDÊNCIA ENTRE AMORIM GIRÃO E GONZALO DE REPARAZ RUIZ
}

\author{
João Carlos Garcia/garciajcs@hotmail.com
}

Faculdade de Letras da Universidade do Porto e Centro Interuniversitário de História das Ciências e da Tecnologia (UL/UNL)

Enric Mendizàbal Riera/enric.mendizabal@uab.es

Facultat de Filosofia i Lletres Universitat Autònoma de Barcelona

$\mathrm{Na}$ Cartoteca do Institut Cartogràfic i Geològic de Catalunya, em Barcelona, encontra-se um importante núcleo documental para a História da Geografia Iberoamericana: o Fons Gonzalo de Reparaz Ruiz (1901-1984) cedido à instituição pela família do geógrafo em 2005. Dele fazem parte milhares de documentos manuscritos e impressos, de fotografias e cerca de 3.000 volumes da sua biblioteca pessoal, até então guardados em Lima (Perú), onde o autor residiu exilado, desde 1951. No espólio existe igualmente documentação relativa a seu pai, Gonzalo de Reparaz Rodríguez-Báez (1860-1939), também geógrafo, diplomata e jornalista, nascido no Porto, onde participou na fundação da efémera Sociedade de Geografia Comercial do Porto, sob a presidência de Oliveira Martins, em 1880. As relaçóes da família Reparaz com Portugal abarcam três geraçóes e incluem muitos dos mais importantes intelectuais portugueses do final do século xIX e da primeira metade do século Xx. 
Entre os diversos tipos de documentos conservados avultam os núcleos de correspondência trocada com políticos, académicos e artistas. Aí procurámos os geógrafos portugueses e, particularmente, o mais conhecido e influente nome da escola portuguesa de Geografia, no segundo quartel do século xx: Amorim Girão. As cartas e bilhetes postais enviados por Girão a Reparaz (de Coimbra e Vouzela) e as cópias a papel químico das cartas dactilografadas, apenas algumas, enviadas por Reparaz a Girão (de Barcelona), num total de quase quatro dezenas, correspondem a um restrito período, entre Setembro de 1928 e Janeiro de 1932, mas nelas debatem os correspondentes, muitos aspetos da Geografia coeva, ibérica e internacional: as suas correntes e escolas, autores e obras, instituiçôes e periodismo científico ${ }^{1}$.

Para este volume em memória de António Gama Mendes, que trabalhou entre nós, de forma marcante, sobre a evolução do pensamento geográfico e cultivou a Geografia ibérica, selecionámos para análise, duas das mais interessantes missivas, datadas de Abril de 1929, numa das quais Reparaz solicita a Girão, um breve panorama da Geografia em Portugal, no período em que este consolida o seu magistério na Universidade de Coimbra. É então o momento em que na Universidade do Porto, a Faculdade de Letras se encontrava provisoriamente encerrada por motivos políticos. Na Universidade de Lisboa, Silva Telles, detentor da primeira cátedra de Geografia em Portugal, falecerá no ano seguinte.

Mas falaremos primeiro da Geografia espanhola durante a década de 1920 e de Gonzalo de Reparaz, para compreendermos o contexto da solicitação e o correspondente de Amorim Girão, já que o Mestre da Geografia de Coimbra e a sua obra são suficientemente conhecidos.

\footnotetext{
${ }^{1}$ Institut Cartogràfic i Geològic de Catalunya (ICGC). Cartoteca. Fons Gonçal de Reparaz Ruiz. 3. Correspondència, 42-42c, 1091. Muito recentemente deu entrada na mesma instituição o espólio de Gonzalo de Reparaz Rodríguez-Báez, vindo do Centro Documental de la Memoria Histórica, Salamanca. Queríamos agradecer à Doutora M. Carme Montaner i Garcia, Directora da Cartoteca do ICGC e investigadora do Grup d'Estudis d'Història de la Cartografia da Universitat de Barcelona, todas as facilidades concedidas na consulta e reproduçáo dos documentos do espólio de Gonzalo de Reparaz Ruiz. Sobre o conjunto da correspondência preparamos um estudo mais detalhado e contextualizado.
} 


\section{A Geografia espanhola na década de 1920}

Durante os anos de 1920 e início da década seguinte, a Geografia tinha em Espanha duas vertentes. Por um lado, apresentava-se como um saber baseado na memorização de topónimos relacionados com algum dado estatístico, fosse a altitude de uma montanha ou os habitantes da capital de um país. Este tipo de Geografia era o que se encontrava na maioria dos livros escolares (Capel et al., 1985; Luis Gómez, 1985) e aquele que foi lecionado a quase todos os estudantes por muitas décadas. Por outro lado, esse é o momento da divulgação de novos métodos a partir dos princípios defendidos por Maria Montessori (1870-1952), que propóe uma docência progressista, ativa, participativa, de observação e experimentação, ao mesmo tempo que surge a metodologia geográfica vinda da escola de Paul Vidal de la Blache.

Esta realidade reflete-se nos movimentos de renovação pedagógica defendidos tanto pela burguesia liberal como pelo movimento operário, especialmente o libertário que, entre outras açóes, promove a edição de traduçóes para castelhano das obras de Elisée Reclus (Vicente Mosquete, 1982). Do mesmo modo, nas Escolas Normais, onde eram preparados os futuros professores, começa a difundir-se esta "nova" Geografia, com importantes resultados. Um exemplo dos seus defensores é Pedro Chico Rello, que publicou uma Metodología de la Geografia (1931), que incorpora esta pedagogia renovadora baseada na metodologia vidaliana, especialmente a partir dos trabalhos de Jean Bruhnes.

Se os professores do ensino primário e secundário formavam uma primeira linha de geógrafos, a segunda seria a dos naturalistas, alguns deles professores universitários nas Faculdades de Ciências (Gómez Mendoza y Ortega Cantero, 1992). Uma amostra desta Geografia ambiental incluiria Odón de Buen (1914), um dos introdutores do darwinismo em Espanha e tradutor de Elisée Reclus; Emilio Huguet del Villar (1921) em Biogeografia e, especialmente, em Pedologia; Eduardo Hernández Pacheco (1934) em Geomorfologia; ou ainda Juan Dantín Cereceda (1929) em Fisiografia (Vilà Valentí, 1989).

A Geografia universitária nas Faculdades de Letras era escassa e, em alguns casos, de pouca qualidade. Durante o período analisado existiam quatro 
catedráticos: Emilio Bullón (Madrid), Amando Melón (Valladolid), Angel Bozal (Sevilha) e Eduardo Pérez Agudo (Barcelona). Este último é o exemplo do geógrafo que leciona uma Geografia enciclopédica e de memorização, e que durante o seu tempo de catedrático (1919-1950) não teve nenhum discípulo, divulgando um programa "quase caricatural" da Geografia (Capel, 1976: 9).

$\mathrm{Na}$ Catalunha onde Gonzalo de Reparaz se instalou, existia um importante grupo de geógrafos que eram pedagogos e/ou docentes de escolas superiores à margem da Universidade. Para além de Pere Blasi, deve ser recordado Miquel Santalò (1923) e, especialmente, Pau Vila, com quem Reparaz contactou à sua chegada a Barcelona, no início dos anos 20 .

\section{Gonzalo de Reparaz Ruiz (Sévres, 1901 - Lima, 1984)}

Gonzalo de Reparaz Ruiz forma parte de uma dinastia de geógrafos: o seu pai, Gonzalo de Reparaz Rodríguez (Porto, 1860 - México, 1939) foi um publicista, diplomata e geógrafo espanhol interessado em Geografia Política e colonialismo em Marrocos (Soriano, 1999); e o seu filho, Gonzalo André de Reparaz (Barcelona, 1932-) foi professor de Geografia, atualmente jubilado, do Institut de Géographie de Aix-en-Provence ${ }^{2}$.

Até se fixar com a família em Barcelona, em 1921, Gonzalo de Reparaz não viveu demoradamente em nenhum lugar, em consequência da vida intensa e complexa de seu pai: entre 1901 e 1908 repartiram-se entre Paris e San Sebastián; entre 1908 e 1911, residiram em Tanger; de 1911 a 1913, novamente em Paris, com estadas em Portugal; entre 1913 e 1919 estiveram na América do Sul (Rio de Janeiro, São Paulo, Buenos Aires...); e entre 1919 e 1921 na Suiça (Berna, Friburgo) e na Alemanha (Berlim). Toda esta vida errante fez com que Reparaz

\footnotetext{
${ }^{2}$ Este ponto tem por base os seguintes textos: Soriano (1999) que descreve o espólio de Gonzalo de Reparaz Rodríguez, incluindo informaçáo sobre a sua vida pessoal e científica, assim como de seu filho Gonzalo de Reparaz Ruiz; Nel.lo (1994) que entrevistou Gonzalo André de Reparaz para falar de seu pai, Gonzalo de Reparaz Ruiz e Pau Alegre Nadal (2008).
} 
(filho), soubesse corretamente o português, o cataláo, o castelhano, o francês, o alemão, o italiano, o inglês e um pouco de checo.

Em Barcelona fez-se membro do Centre Excursionista de Catalunya (CEC) onde contactou com Pau Vila, autor de numerosas obras de Geografia da Catalunha, um dos sócios fundadores da Societat Catalana de Geografia, em 1935, e introdutor da Geografia vidaliana em Espanha, graças às suas relaçóes com Raoul Blanchard, discípulo de Vidal de la Blache e professor na Universidade de Grenoble. Blanchard deu conferências e cursos no CEC sobre Geografia Humana, Urbana e da Montanha, entre 1922 e 1931. Nesse período que permaneceu em Barcelona, de onde escreve a Girão, entre 1928 e 1932, como referimos, Gonzalo de Reparaz investigou sobre a História da Geografia, História da Cartografia, Geografia Humana, Geografia Política e Geografia da Catalunha. Escreveu textos de divulgação e fez também traduções científicas ${ }^{3}$.

\section{Duas cartas de geógrafos}

Gonzalo de Reparaz era um jovem professor de Geografia, na Escola de Ciències Socials de Barcelona, quando escreveu (em fluente português) a Amorim Girão, com um pedido particular: um breve panorama do "estado atual dos estudos geográficos em Portugal e da sua situação nas Universidades”. A correspondência ter-se-ia iniciado uns meses antes, quando Reparaz enviara a Girão dois dos seus trabalhos: a Història dels Descobriments Geogràfics (1927), em dois volumes, e um estudo sobre o rio Ter, El Ter i el seu règim (1928a).

Reparaz escreve um mês antes da abertura da grande Exposição Internacional de Barcelona, em Montjuïc. O ambiente náo é exclusivamente de festa para receber Alfonso XIII e o ditador Primo de Rivera. Os estudantes manifestam-se nas ruas e a atuação da polícia náo é pacífica. A Universidade, para a qual

${ }^{3}$ As traduçốes realizadas por Gonzalo de Reparaz foram as seguintes: Albert Demangeon (1928). Bélgica, Países Bajos, Luxemburgo. Barcelona: Montaner y Simón (volume da Geografía Universal dirigida por Paul Vidal de la Blache) e Norbert Krebs (1931). Geografia humana. Barcelona: Labor. 
há muito se pedem reformas, é temporariamente encerrada. Será também por este contexto que Reparaz pede informaçóes sobre a Geografia portuguesa? Ou pensava num possível lugar de professor universitário em Portugal? O geógrafo de Coimbra tinha agora um desafio para responder.

"Barcelona, 12 Abril 1929

\section{Exmo Amigo:}

Meu obrigado pela sua carta de 3 do corrente e pelas amáveis phrases que contam a respeito da minha "Plana de Vich"4.

Recebi, com efeito, a sua interessantíssima monographia sobre "Viseu" que li com a maior attenção ${ }^{5}$. É de grande interesse e esgota o assumpto. [?], especialmente, as investigaçôes que fez sobre a Viseu romana, e que, aproveitarei para a Encyclopedia Espasa, que justamente me encarregou de escrever esta parte do artigo "Viseu"6. Nem precisa accrescentar que terei o maior prazer em me occupar da sua bellissima monographia, bem assim como das outras publicaçóes enviadas, na Bibliographie Géographique. ${ }^{7}$ - Seria bem preciso que os geógraphos portuguezes tivessem para os seus trabalhos uma publicação mais frequente e abundante que as "Memorias", ou, se quizer, umas "Memorias" mais frequentes e abundantes. Talvez, no futuro, se possa chegar a este desideratum?8

A observação que o meu Exmo. Amigo me faz não é para para [sic] ser facilmente discutida n'uma carta. É antes assumpto para algum longo cavaco

\footnotetext{
${ }^{4}$ G. de Reparaz, 1928b. Ver nota 10.

${ }^{5}$ A. Girão, 1925. Trata-se da dissertaçáo de concurso para Assistente da Faculdade de Letras da Universidade de Coimbra, V Grupo - Geografia.

${ }^{6}$ Foi publicado na Enciclopedia Universal..., vol. 69, 1930, p. 404-405.

7 Bibliographie Géographique Internationale (BGI). Desde 1895, separata de Annales de Géographie. Desde 1921, publicação autónoma - Bibliographie Géographique -, sob coordenação da Association de Géographes Français. Desde 1932 tem o título de BGI. Só desde 1949 a Union Géographique Internationale passa a controlar a publicação. Reparaz seria entâo um dos correspondentes espanhóis do periódico.

${ }^{8}$ Só em 1950 será criada uma revista universitária de âmbito geográfico, o Boletim do Centro de Estudos Geográficos, coordenado por Amorim Girão, na Universidade de Coimbra, que se publicará até 1966/67. As Memórias e Notícias. Publicações do Museu Mineralógico e Geológico da Universidade de Coimbra, existentes desde 1921, só a partir de 1932 passarão a ser uma publicação periódica.
} 
entre ambos, que espero ainda se apresentará, um dia ou outro, a occasiáo de ter-mos. A observação que V. ${ }^{\text {a }}$ Ex. ${ }^{\mathrm{a}}$ me faz - digamos - por excesso (estar demais a geographia social e a evolução demographica), fil-a eu, por falta, na "Bacia do Vouga”, como sem dúvida o meu Exmo. Amigo viu na critica que fiz na "Bibliographie Géographique"9. É ahi que está a differença maior entre ambas as nossas tendências geográficas, talvez. Mas afinal de contas é apenas um detalhe, talvez secundário. - Ainda assim quero fazer notar ao meu amigo que eu fizera preceder o capitulo da geographia social de três ou quatro paginas explicativas, que supprimi a pedido do editor, quem me pedia para não fazer theoria n'uma obra que correspondia a uma serie como a "Enciclopedia Catalunya" ${ }^{10}$. Eis uma das razóes que n'este caso me impediram de dar a conhecer a minha opinião ao respeito. Aliás creio do maior interesse conhecer com exactidão a distribuição da população humana - deixando-a fixada n'um momento dado - e a sua evolução, visto que esta e as suas modalidades diversas pode obrigar-nos a buscar as causas das anomalias na evolução da distribuição geographica e suas causas... Poder-lhe-ia fazer outras muitas observaçóes que se me occorrem... Mas iria muito longe e prefiro deixa-lo para quando possamos falar largamente e com toda a calma.

Com effeito, creio que um analphabeto a escrever sobre coisas que não entende nem se tomou o incomodo de estudar, como foi o caso do Fidelino de

9 Sobre A Bacia do Vouga (1922), dissertação de Doutoramento em Geografia, de Amorim Girão, a primeira em Portugal, comentara Reparaz na Bibliographie Géographique: "La thèse de Mr. Amorim Girão est un étude approfondie et détaillé d'une région du Portugal fort interessante: le bassin du Vouga. L'auteur l'a étudié soigneusement et en détail, sauf l'évolution de la population, qu'il aurait peut-être pu examiner un peu plus à fond, en y ajoutant quelques donnés statistiques, qui manquent. La partie physique et climatique est três complete, ainsi que l'étude économique de la région." (vol. XXXVII, 1927, p. 351). Na biblioteca de Reparaz depositada no ICGC existe o exemplar da obra enviado por Girão a Reparaz, com a seguinte dedicatória: "Ao Exmo Senhor D. Gonçalo de Reparaz (filho) homenagem e agradecimento de A. de Amorim Girão. Coimbra, 12.10.1928".

10 A "Col.lecció Popular Barcino" e a "Enciclopedia Catalunya" foram duas coleçôes de obras publicadas pela editora Barcino, fundada em 1924. Na primeira, entre outros títulos, foi difundido o Resum de Geografia de Catalunya (9 vols.), de Pau Vila, entre 1929 e 1936; na segunda, publicaram-se manuais e estudos de Ciências Sociais sobre a Catalunha. A secção de Geografia da coleção, foi dirigida por Pau Vila, que solicitou a Reparaz uma monografia sobre a Plana de Vic (1928b). Sobre a história da editora ver Manent, 1980. 
Figueiredo, merecia a sova que lhe dei. Estimei bem que V.a Ex. ${ }^{a}$ gostasse do meu artigo e que o achasse oportuno ${ }^{11}$. Só pretendi fazer justiça...

E a propósito: teria o meu prezado amigo a bondade de me dar alguns detalhes sobre o estado actual dos estudos geographicos em Portugal e da sua situação nas Universidades? Isto completaria muito útilmente o que eu já sei a respeito.

Tornei domingo da excursão da U.G.F.L. (Union Géographique de la Faculté de Lettres), que fez um grupo de 36 estudantes da Sorbonne pelo Rosselhão ${ }^{12}$. Entre elles havia 22 geographas! É o meu amigo ver as sympatias que em França sente o elemento feminino pela geographia! Penso occupar-me d'isto na "Seara"13. No entanto tomo a licença de enviar a $V .^{a}$ Ex. ${ }^{a}$ um artigo que publiquei ontem sobre esta pittoresca e útil excursão ${ }^{14}$. Talvez lhe interesse.

Tive um verdadeiro prazer sabendo que, já está muito melhor. Espero que prestes estará totalmente restabelecido para bem da geographia portugueza.

Repetindo-lhe os meus sinceros agradecimentos pelas suas amáveis phrases, repito-me, como sempre, de V. ${ }^{a}$ Ex. ${ }^{a}$ muito dedicado amigo e admirador".

Amorim Girão responde duas semanas depois. A crítica à "Geografia Social” de Reparaz com base na Plana de Vic já a tinha feito, a contra-resposta vai agora

11 Reparaz refere-se a uma polémica que travara recentemente com Fidelino de Figueiredo (1888-1967), historiador, crítico literário e político, que se encontrava então exilado em Madrid. Em Agosto de 1928, Figueiredo publicara na Revista de las Españas, de Madrid, um texto intitulado "Parenthesis Anti-Geographico", sobre a Geografia da Península Ibérica e a sua relação com a História. Reparaz fará uma crítica demolidora ao ensaio e ao seu autor, "O Sr. Fidelino Geógrafo", na revista Seara Nova (1929a), citando Girão como "o único professor de Geografia Humana que ensina numa universidade peninsular" e a sua "excelente monografia geográfica sobre a Bacia do Vouga" (1929a, p. 72). De qualquer modo, Figueiredo republicará o texto na coletânea Crítica do Exílio (Lisboa, 1930, pp. 39-74).

12 A U.G.F.L. enquadrava-se na Union Nationale des Étudiants de France (U.N.E.F.), fundada em 1909.

13 Uns meses mais tarde cumprirá a promessa: a Seara Nova publica "Por terras dos Pyrenéus. Uma excursão geográfica” (Reparaz, 1929b), onde além da descrição e enquadramento do evento, o autor relaciona este tipo de atividades com os métodos defendidos por Amorim Girão, recomendando mesmo a leitura da obra Geografia Moderna (Girão, 1917).

14 Procurámos o artigo no espólio de Gonzalo de Reparaz (ICGC) mas, lamentavelmente, sem resultado. 
dentro da publicação sobre o ensino da Geografia, que lhe envia de presente. Aí diz sobre quem defende essa nova visão da Geografia: "[...] confundem, afinal, geografia com antropogeografia, ou, para melhor dizermos, geografia humana, que constitui apenas um ramo dos conhecimentos geográficos, aquele por ventura que tem um cunho menos acentuadamente scientifico. Porque é incontestável que a geografia como sciencia, conforme a própria etimologia do nome indica, tem forçosamente de constituir-se como sciencia da Natureza, ao lado da geologia, por forma que as duas se aliem de maneira a dar-nos a ideia completa e harmónica do organismo cujo estudo tem por objecto - a Terra." (Girão, 1928: $384)^{15}$. Reparaz não terá gostado mas, mais do que debater os temas polémicos, Giráo escreve para o convidar a dar umas aulas na Universidade de Coimbra, sobre História da Geografia. Essa visita acontecerá no ano seguinte, durante os Cursos de Verão, e mudará o percurso de vida de Reparaz.

"Coimbra, 29-IV-929

Meu Exmo Amigo:

Só hoje respondo à sua carta de 12 dêste mês, para poder enviar-lhe juntamente a separata de um artigo que publiquei sôbre o ensino da geografia em Portugal ${ }^{16}$.

Concordo absolutamente com a explicação que dá ao diferente modo de ver que temos àcêrca da discutida geografia social: a diversidade das nossas tendências geográficas! Deve ser isso, com efeito; eu tive por mestre um geólogo ${ }^{17}$, e assim não admira que, através de tudo, procure sempre encarar a geografia como a sciência dos "factos que se inscrevem sobre o solo."

15 Girão continua fiel ao organicismo oitocentista e esta posiçăo contribuirá também para a futura polémica com Orlando Ribeiro, cujas primeiras publicaçōes, em 1934, defendem a importância determinante da Geografia Humana (ver Gama, 1984).

16 Trata-se de "O Ensino da Geografia nos Liceus e nas Universidades" (Girão, 1928).

17 Anselmo Ferraz de Carvalho (1878-1955). Foi Professor Catedrático de Geologia, Paleontologia e Geografia Física da Universidade de Coimbra e Diretor de várias instituições na mesma Universidade: Instituto Geofísico, Observatório Meteorológico, Museu e Laboratório Mineralógico e Geológico e da Faculdade de Ciências. 
Muito agradeço o artigo sobre a notável excursão geográfica da U.G.F.L. ${ }^{18}$ A simpatia, a que alude, do elemento feminino pelos estudos geográficos, também aqui a poderíamos verificar: eu tenho tido cursos por vezes constituídos na sua maior parte por senhoras! ${ }^{19}$

Além das informaçóes contidas no artigo que envio, vou procurar dizer-lhe mais alguma coisa, com a possível imparcialidade.

O ensino superior da geografia em Portugal data, pode dizer-se, da criação das Faculdades de Letras, ou seja, do advento da República ${ }^{20}$. Para a Fac. de Letras de Lisboa, transitaram os profs. do antigo Curso Superior de Letras, e entre eles o Dr. Silva Teles, prof. de Geografia ${ }^{21}$. Para a Fac. de Coimbra transitaram alguns profs. da extinta Fac. de Teologia. O primeiro prof. de Geografia da Fac. de Letras coimbrã foi o Dr. Ferraz de Carvalho, catedrático de Geologia da Fac. de Ciências e meu Mestre ${ }^{22}$. Já não rege todavia cadeira em Letras. A Fac. de Letras do Porto, de criação posterior (1919), e onde ensina Geografia o Dr. Mendes Correia, prof. da Fac. de Sciências, está ameaçada de desaparecer, condenada sobretudo pela falta de critério que presidiu ao recrutamento do seu corpo docente ${ }^{23}$.

18 Union Géographique de la Faculté des Lettres. Ver nota 12.

${ }^{19}$ A presença feminina no âmbito das licenciaturas em Geografia terá ocorrido relativamente cedo, se comparada com a realidade de outros países europeus. Em Portugal, a primeira Doutora em Geografia foi Raquel Soeiro de Brito (1925-), que defendeu a sua dissertação sobre a ilha de Sáo Miguel (Açores), na Universidade de Lisboa, em 1955. Na Universidade de Coimbra, a primeira Doutora em Geografia foi Lucília de Jesus Caetano, em 1986.

20 As Faculdades de Letras das Universidades de Lisboa e Coimbra foram criadas em 1911 e a da Universidade do Porto, em 1919. Amorim Girão contava-se entre os primeiros bacharéis em Ciências Históricas e Geográficas formados pela Universidade de Coimbra, em 1916 (Rebelo, 2008, p. 16). A sua tese de licenciatura versará sobre o conceito e a evolução de "Geografia Moderna" (Girăo, 1917).

${ }^{21}$ Silva Telles detinha desde 1904, a cátedra de Geografia no Curso Superior de Letras, fundado por D. Pedro V, em Lisboa, em 1861 (ver Ribeiro, 1976 e Pimenta, 2004).

22 Ver nota 17.

${ }^{23}$ A Faculdade de Letras do Porto fora provisoriamente encerrada por motivos políticos em 1928, na sequência da revolução do ano anterior, no Porto, contra o novo regime de ditadura militar. Em 1931, no contexto de novos tumultos políticos, a Faculdade será definitivamente encerrada por três décadas (Garcia \& Pimenta, p. 548-549). As matérias geográficas nunca foram aí lecionadas por geógrafos: ao médico, antropólogo e professor da Faculdade de Ciências, A. Mendes Corrêa, nomeado Doutor em Ciências Geográficas pelo Conselho Científico da instituição, em 1925, reuniram-se os historiadores A. Magalhães Basto e Torquato de Sousa Soares, como assistentes. 
Tenho notado que os alunos saídos da Fac. de Lisboa se preocupam mais com questôes de método, denotando uma grande simpatia por Davis ${ }^{24}$; os de Coimbra dão, pelo contrário, mais atençáo a estudos de investigaçáo pessoal, sem preocupação de escolas geográficas ${ }^{25}$.

Pensa-se numa nova reorganização do ensino da geografia nas nossas Universidades, motivada ao que parece pelo meu artigo. Pelo menos, estou colaborando num projecto sôbre o assunto, por incumbência do Ministério da Instrução ${ }^{26}$.

E, a propósito: Como por esta reorganização teremos talvez a criação de cadeiras novas, como História da Geografia, em que se tem especializado, ser-lhe-ia agradável vir aqui um dia fazer algumas liçóes sôbre o assunto? Pensei nisto porque, tendo-me mostrado desejo de vir a Portugal, poderíamos talvez combinar as coisas por forma a juntar o útil ao agradável...27

Ano passado, tivemos em Coimbra a reger cadeira, durante todo o ano em que estive doente, o Prof. Bourdón, director do Instituto Francês em Portugal ${ }^{28}$. Porque náo havia de vir também o meu Exmo Amigo? Eu sou daqueles que muito gostam de ver arejar os cursos, e teríamos assim realizada a melhor forma de intercâmbio intelectual.

\footnotetext{
${ }^{24}$ Girăo refere-se certamente ao geógrafo físico norte-americano William Morris Davis (1850-1934), famoso pela sua teoria do ciclo de erosão. Silva Telles conhecia Davis das reuniôes científicas internacionais e com ele mantinha correspondência (cf. Garcia \& Aurindo, 2004, p. 20).

25 Sobre as correntes teóricas na evoluçấo da Escola de Geografia de Coimbra, ver Almeida et al. (2003) e, particularmente, o estudo de António Gama, 2011.

26 Provavelmente por indicaçáo do Ministro G. Cordeiro Ramos, a quem sucede na pasta, o geógrafo Silva Telles, entre Julho e Setembro de 1929. A reforma foi promulgada em Fevereiro de 1930, individualizando finalmente a licenciatura em Ciências Geográficas. O ensino ficou repartido entre as Faculdades de Letras e de Ciências e a defesa de uma dissertação escrita final tornou-se obrigatória (Medeiros, 2013, p. 958-959).

27 Por indicação de Amorim Girāo, Gonzalo de Reparaz participará como professor, no Curso de Verão da Universidade de Coimbra, em 1930. As críticas não foram as melhores já que tinha sido convidado "um estrangeiro" para reger aulas de Geografia de Portugal. Reparaz, que náo visitava Portugal desde 1913, conheceu em Coimbra a sua futura esposa, Jeanne Chambord, também geógrafa e discípula de Pierre Camena d'Almeida e de Louis Papy.

${ }^{28}$ León Bourdon (1900-1994), especialista de temas da História e da Cultura portuguesas do século XvI, foi Diretor do Institut Français au Portugal (1928-1935) e, posteriormente, professor nas Universidades de Toulouse e Paris (Sorbonne).
} 
Da minha saúde, posso dizer-lhe que isto continua a progredir, embora muito lentamente ${ }^{29}$. Lá vou dando umas pequenas aulas, mas ainda não tenho autorizaçáo do médico para fazer qualquer esforço de maior. Continuo, portanto, sem nada fazer. E logo que o tempo definitivamente se firme, voltarei para a serra, onde me fecharei todo o veráo, a $900 \mathrm{~m}$. de altitude, isolado do mundo. Vamos a ver se, com uma longa estada na altitude, isto entra de novo na normalidade.

Esquecia-me dizer-lhe: Já cá temos a parte publicada da Geografia Universal do Instituto Gallach ${ }^{30}$. Admirável. O seu fascículo de História da Geografia, que fez o favor de enviar-me, está nas mãos do Dr. Ferraz de Carvalho, que muito o apreciou também. É ele que está escrevendo, para a mesma obra, a parte relativa a Portugal ${ }^{31}$.

4-V-929

Circunstâncias várias, obrigam-me, bem contra minha vontade, a só hoje fechar esta carta. Desculpe a demora.

Envio-lhe os melhores cumprimentos, e peço me creia sempre

De V. ${ }^{\text {a }}$ Ex. ${ }^{a}$

Adm.or e m.to at.o e grato am.o

de Amorim Girão"

${ }^{29}$ Amorim Girăo sofria de graves problemas pulmonares.

30 Amorim Girão refere-se a Geografía Universal. Descripción moderna del Mundo publicada pelo Instituto Gallach de Librería y Ediciones, em 5 vols., entre 1929 e 1931. Gonzalo de Reparaz assina no vol. I, o capítulo dedicado à "Historia de la Geografía" (pp. 532-563) e, no volume dedicado à Ásia, África e Oceânia, os textos intitulados "Asia" e "Regiones Polares". Anselmo Ferraz de Carvalho redigiu o capítulo respeitante a Portugal, no volume dedicado à Península Ibérica (pp. 521-587).

31 Ver nota anterior. 


\section{Intercâmbio científico}

Nesse final dos anos 20, em que os países ibéricos viviam sob regimes políticos de ditadura militar, novas ideias científicas circulavam entre alguns investigadores e universitários. Amorim Girão e Gonzalo de Reparaz trocam informações sobre as novidades do saber geográfico - os princípios da escola de Vidal de la Blache, as teorias de William Morris Davis, os estudos recém editados e referidos na Bibliographie Géographique Internationale - e sobre os seus percursos académicos e pessoais. As cartas permitem outra maneira de ver a difusão das ideias, muito mais humana e pessoal, complementando a obtida através das publicaçôes científicas. Na correspondência passa a notícia das importantes relaçóes intelectuais entre Portugal e Espanha e o conhecimento e reconhecimento dos respetivos trabalhos geográficos, onde cabem os pontos de coincidência mas também os desacordos e diferenças de escolas, correntes e metodologias.

Nesse final dos anos 20, os dois geógrafos ibéricos, um mais ligado às ciências naturais e outro às ciências sociais, com formaçōes académicas e opções políticas distintas, discutem a ascensão da Geografia Humana no conjunto do saber geográfico e, particularmente, na Geografia Regional. A Bacia do Vouga e La Plana de Vic servem de palco e de laboratório para testar teorias e práticas e, sobretudo, para os autores discutirem a construção do discurso científico. Como faremos a História da Ciência no futuro, sem o acesso aos e-mails do passado e sem o maço das velhas cartas dos geógrafos?

\section{Bibliografia}

AAVV (1908-1930). Enciclopedia Universal Ilustrada europeo-americana. 72 vols., Barcelona: J. Espasa y Hijos / Madrid: Espasa-Calpe.

Alegre Nadal, Pau (2008). La mirada d'un geògraf, la de Gonçal de Reparaz. Obrador Obert. El Bulletí digital de la SCG, http://scg.iec.cat/Scg9/Scg90/S96241.htm (ultima consulta 27/02/2016). 
Almeida, A. Campar de; Gama, A.; Cravidão, F. D.; Cunha, L. \& Jacinto, R. (2003). Fragmentos de um retrato inacabado. A Geografia de Coimbra e as metamorfoses de um País. Coimbra: Instituto de Estudos Geográficos / Centro de Estudos Geográficos.

Buen, Odón de (1914). Nociones de Geografía Física. Barcelona: La Escuela Moderna.

Capel, H. (1976). La Geografía Española tras la Guerra Civil. GeoCrítica. Cuadernos críticos de Geografía Humana, N.o 1.

Capel, H. et al. (1985). Geografía para todos. La Geografía en la enseñanza española durante la segunda mitad del siglo XIX. Barcelona: Los Libros de la Frontera.

Dantín Cereceda, Juan (1929). Geografía. Madrid: Publicaciones de la Revista de Pedagogía.

Gama, António (1984). Geografia e Civilização: a propósito da teoria geográfica na obra de Orlando Ribeiro. In Livro de Homenagem a Orlando Ribeiro. Lisboa: Centro de Estudos Geográficos, vol. I, pp. 77-88.

Gama, António (2011). Geografia e Geógrafos: institucionalizaçăo e consolidação da Geografia na Universidade de Coimbra. Biblos, vol. Ix, pp. 217-246.

Garcia, João Carlos \& Aurindo, Maria José (2004). Francisco Xavier da Silva Telles. Catálogo da Exposição Bio-Bibliográfica na Sociedade de Geografia de Lisboa. Lisboa: Associação Portuguesa de Geógrafos.

Garcia, Joăo Carlos \& Pimenta, José Ramiro (2004). Os Livros de Geografia da Faculdade de Letras da Universidade do Porto (1919-1931): Ciência, Ensino e Divulgação. In Estudos em Homenagem a Luís António de Oliveira Ramos. Porto: Faculdade de Letras da Universidade do Porto, vol. II, pp. 545-559.

Girão, A. de Amorim (1917). Geografia Moderna. Evolução. Conceito. Relação com outras Ciências. Ensaio de Síntese. Revista da Universidade de Coimbra, vol. vi, pp. 316-340.

Girăo, A. de Amorim (1922). A Bacia do Vouga. Estudo Geográfico. Coimbra: Imprensa da Universidade (Dissertação de Doutoramento em Ciências Geográficas).

Girão, A. de Amorim (1925). Viseu. Estudo de uma aglomeração urbana. Coimbra: Coimbra Editora.

Girão, A. de Amorim (1928). O Ensino da Geografia nos Liceus e nas Universidades. Arquivo Pedagógico. Boletim da Escola Normal Superior de Coimbra, vol. 2, n. o 4, pp. 373-386.

Gómez Medoza, Josefina \& Ortega Cantero, Nicolás [dirs.] (1992). Naturalismo y Geografía en España (desde mediados del siglo XIX hasta la guerra civil). Madrid: Fundación Banco Exterior.

Hernández Pacheco, Eduardo (1934). Síntesis fisiográfica y geológica de España. Madrid: Trabajos del Museo Nacional de Ciencias Naturales, serie geológica, n. ${ }^{\circ} 38$.

Huguet del Villar, Emilio (1921). El valor geográfico de España. Ensayo de ecética. Madrid: Rivadeneyra (2. ${ }^{a}$ ed., Barcelona: Publicacions de la Universitat de Barcelona, 2010).

Luis Gómez, Alberto (1985). La Geografía en el bachillerato español (1836-1970). Barcelona: Publicacions de la Universitat de Barcelona.

Manent, Albert (1980). Josep Maria Casacuberta i l'Editorial Barcino. Barcelona: Associació d'Editors en Llengua Catalana.

Medeiros, Carlos Alberto (2013). Geografia. In Sérgio Campos Matos \& Jorge Ramos do Ó (coord.). A Universidade de Lisboa nos séculos XIX e XX. Lisboa: Tinta da China, vol. II, p. 956$-981$. 
Nel.lo, Oriol (1984). Apunts sobre la vida i l'obra de Gonçal de Reparaz i Ruiz (1901-1984) Una entrevista amb el professor G. André de Reparaz. Treballs de la Societat Catalana de Geografia, n. ${ }^{\circ} 38$, pp. 137-146.

Pimenta, José Ramiro (2004). Traços de uma biografia científica. In Obras de Silva Telles. A Ciência Geográfica. Lisboa: Associação Portuguesa de Geógrafos, pp. I-xxix.

Rebelo, Fernando (2008). A Geografia Física de Portugal na vida e obra de quatro professores universitários. Amorim Girão, Orlando Ribeiro, Fernandes Martins, Pereira de Oliveira. Coimbra: Ediçôes Minerva.

Reparaz Ruiz, Gonzalo (1927). Història dels descobriments geogràfics. Barcelona: Barcino (Col.lecció Popular Barcino).

Reparaz Ruiz, Gonzalo (1928a). El Ter i el seu règim: qüestions geogràfiques. Butlletí del Centre Excursionista de Catalunya, n. ${ }^{\circ}$ 398, pp. 269-272.

Reparaz Ruiz, Gonzalo (1928b). La Plana de Vic. Barcelona: Barcino (Col.lecció Enciclopèdia Catalana). 2.a ed., Vic: Eumo, 1982.

Reparaz Ruiz, Gonzalo (1929a). Geografia hilariante. Seara Nova, Ano VII, n. ${ }^{\circ} 149$, pp. 69-73.

Reparaz Ruiz, Gonzalo (1929b). Por Terras dos Pyrenéus. Uma excursão geográfica. Seara Nova, Ano VIII, n. ${ }^{\circ} 184$, pp. 250-253.

Ribeiro, Orlando (1976). Silva Telles, introdutor do ensino da Geografia em Portugal. Finisterra, XI, 21, pp. 12-36.

Santaló, Miquel (1923). Per l'estudi de Catalunya: concepte de la comarca geogràfica i dels seus factors. Assaig monogràfic: El Gironès. Girona: Talleres gráficos "El Autonomista".

Soriano, Ignacio C. (1999). El archivo de Gonzalo de Reparaz. Documents d'Anàlisi Geogràfica, n. ${ }^{\circ}$ 34, pp. 211-227.

Vicente Mosquete, María Teresa (1983). Eliseo Reclús, la Geografía de un anarquista. Barcelona: Los Libros de la Frontera.

Vilá Valentí, Juan (1989). El conocimiento geográfico de España. Geógrafos y obras geográficas. Madrid: Síntesis. 